\title{
Clinical course and outcome of patients with ACTH-dependent Cushing's syndrome infected with novel coronavirus disease-19 (COVID-19): case presentations
}

\author{
Zhanna Belaya $\mathbb{( D}^{1} \cdot$ Olga Golounina $^{2} \cdot$ Galina Melnichenko $^{1} \cdot$ Natalia Tarbaeva $^{1} \cdot$ Evgenia Pashkova $^{3}$. \\ Maxim Gorokhov ${ }^{1} \cdot$ Viktor Kalashnikov $^{1} \cdot$ Larisa Dzeranova $^{1} \cdot$ Valentin Fadeev $^{2} \cdot$ Pavel Volchkov $^{1,4} \cdot$ Ivan Dedov $^{1}$
}

Received: 28 October 2020 / Accepted: 24 February 2021 / Published online: 13 March 2021

(c) The Author(s), under exclusive licence to Springer Science+Business Media, LLC, part of Springer Nature 2021

\begin{abstract}
Objective To analyze the clinical presentations of patients with endogenous Cushing's syndrome (CS) affected by Coronavirus disease-19 (COVID-19).

Materials and methods Patients who were referred to our clinic with active CS from 31st March to 15th May 2020 were screened for COVID-19 using real-time reverse transcriptase-polymerase chain reaction (RT-PCR). Late-night serum cortisol $(64-327 \mathrm{nmol} / \mathrm{L})$, late-night salivary cortisol (LNSC) $(0.5-9.4 \mathrm{nmol} / \mathrm{L})$, or $24-\mathrm{h}$ urinary free cortisol $(24 \mathrm{hUFC})$ (100-379 nmol/24 h) were measured by electrochemiluminescence immunoassay.

Results Among 22 patients with active CS we found three cases affected by COVID-19. Nonspecific inflammation markers were within the reference range or slightly elevated in these patients. A 71-year-old woman with newly diagnosed CS (latenight serum cortisol $>1750 \mathrm{nmol} / \mathrm{L}$, LNSC $908.6 \mathrm{nmol} / \mathrm{L}$ ) developed dyspnea as an only symptom and died from bilateral polysegmantal hemorrhagic pneumonia 7 days later. A 38-year-old woman with a 5-year medical history of active Cushing's disease (CD) (late-night serum cortisol $581.3 \mathrm{nmol} / \mathrm{L}$, $24 \mathrm{hUFC} 959.7 \mathrm{nmol} / 24-\mathrm{h}$ ) suffered from dyspnea, cough, fever $\left(39.3{ }^{\circ} \mathrm{C}\right)$ and chest pain. Oxygen therapy, antibiotics and symptomatic treatments lead to full recovery 24 days later. A 66year-old woman with a 4-year medical history of mild CD (late-night serum cortisol $603.4 \mathrm{nmol} / \mathrm{L}, \mathrm{LNSC} 10.03 \mathrm{nmol} / \mathrm{L}$ ) tested positive for COVID-19 in routine screening and remained asymptomatic.

Conclusions The outcome of COVID-19 in patients with CS depends on the severity of hypercortisolism. Thus, severe hypercortisolism is a warning sign that CS affected by COVID-19 could require emergency care despite a lack of clinical presentations and low inflammation biomarkers.
\end{abstract}

Keywords COVID-19 $\cdot$ SARS-CoV-2 $\cdot$ ACTH-dependent Cushing's syndrome $\cdot$ Cushing's disease $\cdot$ Pneumonia

Zhanna Belaya

jannabelaya@gmail.com

1 The National Medical Research Center for Endocrinology, Moscow, Russia

2 I.M. Sechenov First Moscow State Medical University of the Ministry of Health of the Russian Federation (Sechenov University), Moscow, Russia

3 Clinical State Hospital named after SP Botkin, Moscow, Russia

4 Life Sciences Research Center, Moscow Institute of Physics and Technology, Dolgoprudniy, Russia

\section{Introduction}

Coronavirus disease-19 (COVID-19) is a novel viral pandemic disease caused by severe acute respiratory syndromeCoronavirus-2 (SARS-CoV-2) [1]. According to the World Health Organization, (WHO) more than $80 \%$ of patients have mild symptoms or are asymptomatic and $\sim 14 \%$ suffer a severe course of the disease and require hospitalization. However, 5\% may suffer critical illness with multiple organ dysfunction syndrome (MODS), acute respiratory distress syndrome (ARDS), and death (https://www.who. int/emergencies/diseases/novel-coronavirus-2019/situationreports/). Common symptoms in hospitalized patients are fever (70-90\%), dry cough (60-86\%), shortness of breath (53-80\%), fatigue (38\%), and myalgias (15-44\%), which 
coincided with laboratory abnormalities such as lymphopenia (83\%), elevated inflammatory markers (e.g. Erythrocyte sedimentation rate (ESR), C-reactive protein (CRP), ferritin, Interleukin-1 (IL-1), IL-6 etc.) and abnormal coagulation parameters [2-4].

It is currently believed that a key step in developing severe COVID-19 is immune dysfunction resulting in «cytokine storm syndrome» which is a variety of systemic inflammatory response syndrome $[2,5,6]$. Based on a cohort study, COVID-19 associated hyperinflammatory syndrome (cHIS) was recently defined using a six-criterion additive scale: fever $>38.0^{\circ} \mathrm{C}$, macrophage activation (ferritin of $700 \mu \mathrm{g} / \mathrm{L}$ or more), hematological dysfunction (neutrophil to lymphocyte ratio of 10 or more), hepatic injury (lactate dehydrogenase of $400 \mathrm{U} / \mathrm{L}$ or more or aspartate aminotransferase $100 \mathrm{U} / \mathrm{L}$ or more), coagulopathy (D-dimer of $1.5 \mu \mathrm{g} / \mathrm{mL}$ or more) and cytokinaemia (CRP of $15 \mathrm{mg} / \mathrm{dL}$ or more, IL-6 of $15 \mathrm{pg} / \mathrm{mL}$ or more or triglycerides of $150 \mathrm{mg} / \mathrm{dL}$ or more) [7]. This scale shows association with COVID-19 progression to mechanical ventilation and death [7].

Currently, glucocorticoids (GCs) have proven to be effective at preventing death in patients requiring respiratory support in a randomized control trial [8]. Exogenous GCs were reported to reduce CRP and IL-6 plasma levels in patients with COVID-19, without affecting virus clearance $[9,10]$. Currently the WHO guidance strongly recommends systemic GC therapy for 7-10 days in patients with severe and critical COVID19 [11]. Synthetic GCs such as dexamethasone may have different effects from cortisol in immune cells [12]. Nevertheless, the first description of the anti-inflammatory effects of cortisol was done in 1949 by Hench et al. [13], who reported that high levels of cortisol in patients with endogenous Cushing's syndrome (CS) exerted an anti-inflammatory effect in a subset of patients also suffering from rheumatoid arthritis.

$\mathrm{CS}$ is a rare disorder with an estimated prevalence of around 40 cases per million [14]. In around $80 \%$ of cases, CS is caused by overproduction of adrenocorticotropic hormone (ACTH) by pituitary adenoma (Cushing's disease (CD)) or carcinoid tumor (ectopic ACTH syndrome (EAS)) and in $20 \%$ of cases it is caused by cortisol excess caused by adrenal tumor or hyperplasia [14]. Chronic hypercortisolism provokes the alteration of all neutrophil functions, significantly hindering the immune response, predisposes to atypical presentations of infectious disease and opportunistic infections [14, 15]. Additionally, patients with CS have several comorbidities such as obesity, arterial hypertension, diabetes mellitus (DM), coagulopathy, myopathy, depression, and neuropsychiatric disorders [16], which potentially predisposes patients with CS to a severe course of COVID-19 [17]. Due to a compromised immune system in patients with CS, restrictions in diagnostic and invasive treatment procedures were recommended to prevent risk of transmission [18, 19]. However, with the recent evidence on the positive effects of
GCs in severe cases of COVID-19 [8, 11], it could be speculated that patients with active CS may have a reduced chance of developing cytokine storm and ARDS in case of COVID-19. Nevertheless, there is limited data on patients with CS affected by COVID-19 [20, 21].

In this case series we describe three clinical presentations of COVID-19 confirmed by real-time reverse transcriptase-polymerase chain reaction (RT-PCR) in patients with active CS.

\section{Materials and methods}

An observational study describing a case series of patients with active CS affected by COVID-19 enrolled from the referral population of the National Medical Research Centre for Endocrinology (NMRCE) from 31st March to 15th May 2020.

The patients were included based on a positive COVID19 test and clinically and biochemically confirmed active CS. Diagnosis of COVID-19 was based on positive results for SARS-CoV-2. Two nasopharyngeal and oropharyngeal throat swab samples were collected from each patient and tested for SARS-CoV-2 using RT-PCR.

Diagnosis of CS was based on at least two of the following tests: 24-h urinary free cortisol ( 24 hUFC) above the reference range, late-night serum cortisol at 23:00, latenight salivary cortisol (LNSC), non-suppression of morning serum cortisol lower than $50 \mathrm{nmol} / \mathrm{L}$ in a low-dose $(1 \mathrm{mg})$ dexamethasone suppression test (LDDST) in accordance with Russian and international guidelines [22-24].

The study was approved by the NMRCE local ethical committee. The patients were anonymously registered after providing general informed consent that their data could be used for research purposes.

The following clinical data were analyzed: age, sex, comorbid conditions, symptoms of respiratory infections, laboratory results, and clinical outcomes.

Hormonal assessment was performed by electrochemiluminescence immunoassay for ACTH (reference range: morning 7.2-63.3 pg/mL, late-night at 23:00 h 2-25.5 pg/mL), serum and salivary cortisol (late-night serum cortisol at $23: 00 \mathrm{~h}(64-327 \mathrm{nmol} / \mathrm{L}), \mathrm{LNSC}$ at $23: 00 \mathrm{~h}(0.5-9.6 \mathrm{nmol} / \mathrm{L})$ [25], serum cortisol after LDDST (cut-off value for suppression $50 \mathrm{nmol} / \mathrm{L}$ )) on Cobas e601 automated analyzer. The 24 hUFC (reference range (100-379 nmoL/24-h)) was measured by immunochemiluminescence assay on Vitros ECi.

All patients underwent a chest computed tomography (CT) scan. All lung images were analyzed by radiologists, focusing on the lesion features of each patient, including distribution characteristics, number of lobes involved, and other findings such as pleural effusion, pericardial effusion, or pulmonary emphysema. 
Table 1 Clinical and radiological characteristics of patients with ACTH-dependent Cushing's syndrome and concomitant SARS-2-CoV

\begin{tabular}{|c|c|c|c|}
\hline & Patient 1 & Patient 2 & Patient 3 \\
\hline Gender & Female & Female & Female \\
\hline Age, years & 71 & 38 & 66 \\
\hline Body mass index & $33.8 \mathrm{~kg} / \mathrm{m}^{2}$ & $32.5 \mathrm{~kg} / \mathrm{m}^{2}$ & $33.7 \mathrm{~kg} / \mathrm{m}^{2}$ \\
\hline \multicolumn{4}{|l|}{ Comorbidities } \\
\hline - Hypertension & Yes & Yes & Yes \\
\hline - Diabetes mellitus & Yes & No & Yes \\
\hline $\begin{array}{l}\text { - Cardiovascular } \\
\text { disease }\end{array}$ & Yes & No & Yes \\
\hline \multicolumn{4}{|l|}{ Symptoms } \\
\hline - Fever & No & Yes & No \\
\hline - Cough & No & Yes & No \\
\hline - Dyspnea & Yes & Yes & No \\
\hline Chest CT scan & $\begin{array}{l}\text { Bilateral diffuse areas of } \\
\text { GGOs and consolidations, } \\
\text { bilateral pleural and } \\
\text { pericardial effusion }\end{array}$ & $\begin{array}{l}\text { Bilateral diffuse } \\
\text { areas of GGOs with } \\
\text { subpleural } \\
\text { distribution }\end{array}$ & $\begin{array}{l}\text { Bilateral areas of single } \\
\text { GGO and consolidation } \\
\text { with subpleural } \\
\text { distribution }\end{array}$ \\
\hline $\begin{array}{l}\text { Degree of lungs } \\
\text { involvement }\end{array}$ & $80 \%$ & Not available & $4 \%$ \\
\hline $\begin{array}{l}\text { Supplementary } \mathrm{O}_{2} \\
\text { requirement }\end{array}$ & Yes & Yes & No \\
\hline $\begin{array}{l}\text { Length of stay, days } \\
\text { after diagnosis of } \\
\text { COVID-19 }\end{array}$ & 7 & 24 & 10 \\
\hline Status & Dead & Alive, discharged & Alive, discharged \\
\hline
\end{tabular}

$C T$ computed tomography, $G G O$ ground-glass opacity

\section{Results}

From 31st March to 15th May 2020, there were 22 cases of patients with active CS referred to our tertiary referral clinic. Among them we found three cases of active CS and COVID-19 confirmed by SARS-CoV-2 RT-PCR tests.

The patients' general characteristics and clinical presentations at the time of SARS-CoV-2 diagnosis are summarized in Table 1 . The available laboratory findings for all three cases are presented in Table 2. The activity level of hypercortisolism was assessed just before COVID-19 diagnosis in case 1, 3 weeks after recovery in case 2 and during the course of COVID-19 in case 3 .

\section{Case 1}

A 71-year-old woman with a 20-year medical history of type 2 diabetes mellitus (T2DM) was admitted to our department in April 2020. The patient had previously been under observation in our clinic due to T2DM and her most recent visit as an outpatient for routine evaluation in January 2020 showed no signs of CS which suggested that the duration of CS was less than 3 months. At the time of admission, the patient was immobilized due to profound weakness; morning cortisol levels $1750 \mathrm{nmol} / \mathrm{L}$, potassium
$1.75 \mathrm{mmol} / \mathrm{L}$. Further laboratory tests confirmed ACTHdependent endogenous CS (Table 2. (Case 1)). In addition to this the patient had elevated chromogranin A- $4.6 \mathrm{nmol} /$ $\mathrm{L}$ (reference range $<2.0$ ). EAS was suspected, but on total body CT and MRI there were no signs of tumor or pneumonia.

Due to acutely developing life-threatening complications such as hypokalemia, anemia, hypoalbuminemia, hyperglycemia $(17 \mathrm{mmol} / \mathrm{L})$, and renal failure (glomerular filtration rate $-22 \mathrm{~mL} / \mathrm{min} / 1.73 \mathrm{~m}^{2}$ ) the patient was admitted to an intensive care unit in order to prepare for a life-saving bilateral adrenalectomy. We intended to lower cortisol levels in this case, but etomidate is not available in Russia and due to the severe course of the disease, oral medications and pasireotide were not initiated in the emergency care unit.

On the 7th day of hospitalization, she was re-located to another hospital because our surgical building had become an infection clinic to provide care for COVID-19 patients. On the 13th day of hospitalization, the patient's condition deteriorated due to dyspnea and she tested positive for SARS-CoV-2 for the first time. A chest CT scan showed bilateral diffuse ground-glass opacities (GGOs) and bilateral pleural and pericardial effusion. Despite this, her body temperature and nonspecific inflammation markers remained normal (Tables 1 and 2). 
Table 2 Laboratory characteristics of patients with ACTH-dependent Cushing's syndrome with confirmed COVID-19 pneumonia

\begin{tabular}{lllll}
\hline & Patient 1 & Patient 2 & Patient 3 & Reference range \\
\hline ACTH morning & 445.8 & 74.42 & 25.67 & $7.2-63.3 \mathrm{pg} / \mathrm{mL}$ \\
ACTH at 23:00 h & - & 66.27 & 15.06 & $2-25.5 \mathrm{pg} / \mathrm{mL}$ \\
Late-night serum cortisol at 23:00 h & $>1750$ & 581.3 & 420.2 & $64-327 \mathrm{nmol} / \mathrm{L}$ \\
Late-night salivary cortisol at 23:00 h & 908.6 & 9.05 & 10.03 & $0.5-9.65 \mathrm{nmol} / \mathrm{L}$ \\
Serum cortisol after LDDST & $>1750$ & 747.4 & 603 & $<50 \mathrm{nmol} / \mathrm{L}$ \\
24-h urinary free cortisol & - & 959.7 & 286.2 & $100-379 \mathrm{nmol} / \mathrm{L}$ \\
Hemoglobin A1c (HbA1c) & 8.0 & NA & 7.6 & $4-6 \%$ \\
Hemoglobin & 82 & 104 & 113 & $112-153 \mathrm{~g} / \mathrm{L}$ \\
WBC & 12.4 & 8.11 & 9.44 & $3.4-10.8 \times 10^{9} / \mu \mathrm{L}$ \\
RBC & 2.92 & 4.44 & 5.01 & $3.8-5.2 \times 10^{12} / \mu \mathrm{L}$ \\
ANC & 11.18 & 6.8 & 6.35 & $1.5-6.8 \times 10^{9} / \mu \mathrm{L}$ \\
Lymphocyte count & 0.78 & 0.63 & 2.09 & $0.86-4.07 \times 10^{9} / \mu \mathrm{L}$ \\
Neutrophil to lymphocyte ratio & 14.3 & 10.7 & 3.0 & - \\
Platelet & 73 & 247 & 424 & $152-372 \times 10^{9} / \mu \mathrm{L}$ \\
Hemoglobin & 82 & 104 & 113 & $112-153 \mathrm{~g} / \mathrm{L}$ \\
ESR & 2 & 75 & 50 & $2-30 \mathrm{~mm} / \mathrm{h}$ \\
Total protein & 44 & 70.5 & - & $64-83 \mathrm{~g} / \mathrm{L}$ \\
C-reactive protein & 4.3 & 33.5 & 5.2 & $0.1-5.0 \mathrm{mg} / \mathrm{L}$ \\
Ferritin & 968.4 & - & 37.7 & $20-300 \mathrm{ng} / \mathrm{mL}$ \\
Lactate dehydrogenase & 481.2 & - & 209 & $125-220 \mathrm{U} / \mathrm{L}$ \\
Aspartate aminotransferase & 29 & 28 & 15 & $5-34 \mathrm{U} / \mathrm{L}$ \\
Prothrombin time & 12.8 & 11.4 & 11.1 & $9.4-12.5 \mathrm{~s}$ \\
D-Dimer & 310 & - & - & $0-230 \mathrm{ng} / \mathrm{mL}$ \\
Potassium & 1.7 & 4.6 & 4.2 & $3.5-5.1 \mathrm{mmol} / \mathrm{L}$ \\
SARS-CoV-2 test & Positive & Positive & Positive & \\
\hline ACTH arenocorticotropic & & & \\
\hline
\end{tabular}

$A C T H$ adrenocorticotropic hormone, $L D D S T$ low-dose $(1 \mathrm{mg})$ dexamethasone suppression test, WBC white blood cells, $R B C$ red blood cells, $A N C$ absolute neutrophil count, ESR erythrocyte sedimentation rate, $N A$ not applicable (the patient had normal glucose levels, including glucose tolerability test), —not available in due to COVID-19
The patient had a very high neutrophil to lymphocyte ratio-14, anemia and low platelet count, elevated ferritin and slightly elevated lactate dehydrogenase, however aspartate aminotransferase, CRP and ESR were within the reference range (Table 2). In accordance with cHIS criteria [7] the patient had hematological dysfunction with all the other parameters lower than suggested for COVID-19associated hyperinflammation syndrome. In spite of this, the patient's respiratory status rapidly deteriorated over the next 4 days, progressing to ARDS requiring artificial ventilation. Due to worsening of respiratory symptoms, CT scans were repeated 3 days later and showed multifocal pneumonia with $80 \%$ affected lung tissue (Fig. 1).

The patient received all possible supportive care with potassium levels reaching $3.5-3.6 \mathrm{mmol} / \mathrm{L}$; glucose levels $8-10 \mathrm{mmol} / \mathrm{L}$. She was also tested for $\operatorname{IgM}$ and $\operatorname{IgG}$ for Chlamydia pneumonia and Mycoplasma pneumonia, both of which were negative. The patient went into cardiac arrest

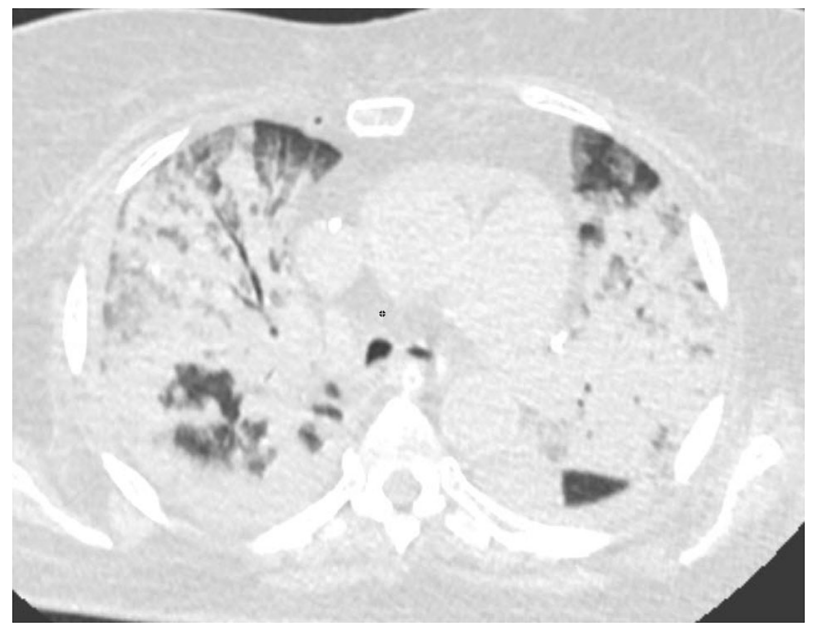

Fig. 1 Patient 1 computed tomography (CT) of the lungs 3 days before death. Chest CT with diffuse bilateral pneumonia and air bronchograms in right upper lobe 
and died despite all supportive therapy 7 days after COVID19 was confirmed on RT-PCR. The officially certified cause of death was COVID-19 complicated by bilateral polysegmental hemorrhagic pneumonia and ARDS with CS as a concomitant disease. There was no mention of an ACTHproducing tumor in the post-mortem report which might be related to the small tumor size or to the specific infection conditions which does not support sufficiently careful examination of patients with COVID-19.

\section{Case 2}

A 38-year-old woman with CD who had been under observation in our clinic for 5 years. Two transsphenoidal neurosurgeries between 2015 and 2020 proved the presence of an ACTH-producing pituitary tumor confirmed by immunohistochemistry. Neurosurgery was first performed in May 2015 revealing ACTH-secreting pituitary adenoma with $\mathrm{Ki}-67=9.11 \%$. A short period of cortisol normalization was followed by an active stage of disease and in November 2017 a second neurosurgery was performed (the removed tissue was basophil ACTH-producing pituitary adenoma; Ki-67 $=30.2 \%$ ) with temporary normalization of cortisol levels followed by an active stage of disease. During the 5 years of observation the patient was prescribed pasireotide and ketoconazole. However, due to poor tolerability she declined taking medication to resolve hypercortisolism. Repeated tests in 2019 showed 24 hUFC $1239 \mathrm{nmoL} / 24 \mathrm{~h} ; 2750 \mathrm{nmoL} / 24 \mathrm{~h}$; LNSC - $14.78 \mathrm{nmol} / \mathrm{L}$ ) which proved active hypercortisolism. Three weeks after the patient was discharged from the COVID-19 clinic, the evaluation confirmed active CD (Table 2). The patient suffered from mild hypertension and obesity. Radiosurgery was postponed due to COVID-19.

In April 2020 the patient was hospitalized, tested positive for SARS-CoV-2 with dyspnea, cough, chest pain, and

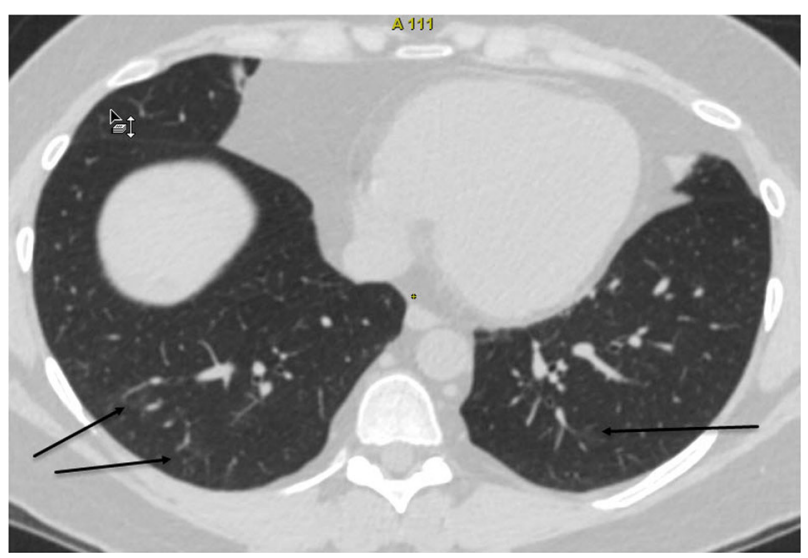

Fig. 2 Patient 2 computed tomography (CT) of the lungs 1 month after COVID-19 recovery. Resolution of consolidation with minimal residual ground-glass opacities (arrows) fever with a maximum temperature of $39.3{ }^{\circ} \mathrm{C}$ (Table 1). A CT scan showed bilateral GGOs of both lungs. Oxygen therapy, antibiotic and symptomatic treatments with paracetamol were initiated. Significant clinical improvement was achieved on the 14th day of hospitalization. She was discharged from hospital on day 24 without symptoms after being double tested negative for SARS-CoV-2. Three weeks later a CT scan showed only very mild signs of lung fibrosis, suggesting a full recovery (Fig. 2).

\section{Case 3}

A 66-year-old woman with confirmed $\mathrm{CD}$ who had been under observation in our clinic for 4 years. CD was confirmed when she was 62 years old based on bilateral inferior petrosal sinus sampling and following histological evaluation after neurosurgery. She achieved clinical and biochemical improvement after a transsphenoidal adenomectomy at 62. However, slightly increased $24 \mathrm{hUFC}$ (388.8 nmoL/24-h; $465.29 \mathrm{nmoL} / 24-\mathrm{h}$ and late-night serum cortisol- $350.3 \mathrm{nmol} / \mathrm{L} ; \quad 494 \mathrm{nmol} / \mathrm{L}$ levels above the reference range remained over 4 years of observation. Her LDDST never returned to full suppression. This patient was prescribed pasireotide, but declined this medication.

Six months before the COVID-19 pandemic, active CD was confirmed based on increased $24 \mathrm{hUFC}$ above the reference range and negative LDDST. MRI scans did not show any signs of pituitary lesion. The patient had a minimum 20-year medical history of T2DM, hypertension, and cardiovascular disease.

She tested positive for SARS-CoV-2 at a routine screening in May 2020. A chest CT scan showed typical signs of pneumonia with $4 \%$ lung involvement (Fig. 3). The patient was hospitalized in order to prevent possible complications. Compared to the previous CS evaluation, $24 \mathrm{hUFC}$ was within the reference range, however late-night serum cortisol was elevated and LDDST was negative (Table 2). On admission, review of her respiratory and cardiovascular systems showed no signs of abnormalities. Her vital signs were stable, with no fever $\left(t=36.5^{\circ} \mathrm{C}\right)$, cough, or difficulty breathing. The patient had slightly elevated ESR and all other results within the reference range (Table 2). The patient received her usual insulin and hypotensive treatment. She made a full recovery after 10 days, remaining asymptomatic.

\section{Discussion}

This case series represents different presentations and outcomes of patients with active CS affected by COVID-19. At the time of our observational study, there were no established effective treatments for COVID-19 and our patients 

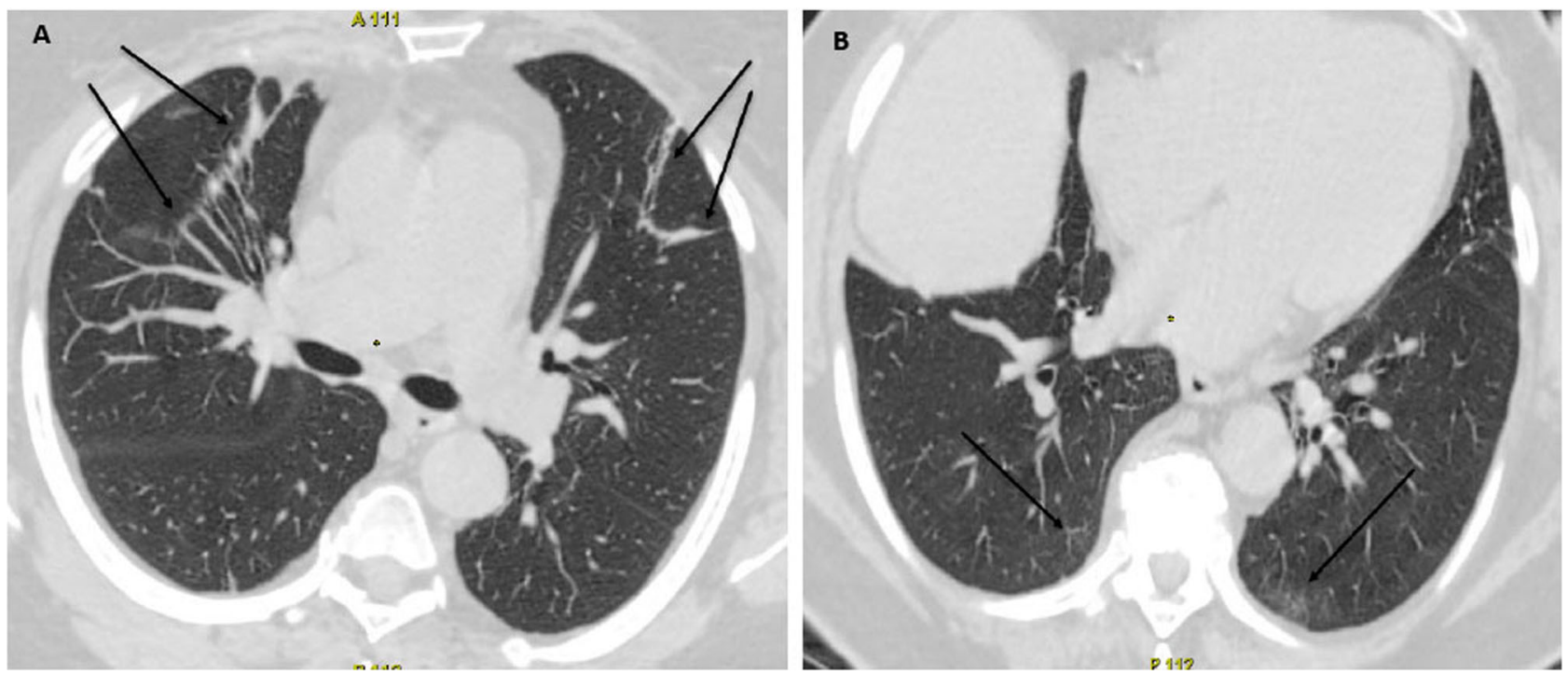

Fig. 3 Patient 3 computed tomography (CT) of the lungs at the time of COVID-19 diagnosis. A CT, axial images. Subsegmental fibroatelectasis (arrows). B CT, axial images. Residual ground-glass opacities with subpleural bands (arrows)

with endogenous hypercortisolism received only symptomatic and supportive care.

The chronic impairment of lymphocyte maturation and differentiation [15], a large decrease in B- and Tlymphocytes and natural killers, a lack of T-helper cell activation may favor opportunistic and intracellular infection $[15,26]$ and may lead to a worse COVID-19 prognosis in patients with CS. In addition to this, cardiovascular complications amplified by an increased thromboembolic risk are the two leading causes of death in patients with CS [19].

Nevertheless, GCs inhibit the expression of many proinflammatory cytokines including IL-1-6; IL-11-13; IL$16-17$, interferon- $\gamma$, tumor necrosis factors- $\alpha$, granulocytemacrophage colony-stimulating factor $[15,26]$. GCs also downregulate the production of several chemoattractants and suppress CD4 $+\mathrm{T}$-cell activation [27], which make GCs potentially beneficial in patients suffering from a pathologic immune reaction [19].

Currently, RECOVERY is the only prospective randomized trial, in which 2014 patients affected by COVID-19 were randomized to dexamethasone $6 \mathrm{mg}$ per day (oral or intravenous) for 10 days and compared to 4321 patients receiving usual care. Evaluation at 28 days found a significant $35 \%$ reduction in mortality amongst patients receiving invasive mechanical ventilation $(p=0.003)$ and by $20 \%$ among patients on supplemental oxygen therapy ( $p$ $=0.0021)$. No benefit was observed in mild or moderate cases, which did not require oxygen support $(p=0.14)$ [8].

Of the five previous studies (four retrospective and one quasi-prospective study) conducted with GCs, three trials showed benefits, whereas two trials showed no benefit in COVID-19 patients [28-32]. A common pattern evolving from these retrospective trials suggests more benefit from low dose GCs compared to high dose GCs [27]. In our case series, extremely high cortisol levels in case 1 were clearly not beneficial as this patient had fulminant progression of lung damage.

Preliminary observations suggest that COVID-19 pneumonia in patients with cardiac diseases, hypertension, diabetes, or immunodeficiency syndromes can more easily become a critical illness or cause death [33]. Previous studies also confirmed that age, lymphopenia, thrombocytopenia, leukocytosis, elevated D-dimer, and prolonged prothrombin time have been associated with higher risk of fatality from COVID-19 [4, 34]. Most of these negative risk factors were presented in case 1 . In addition to this, severe hypercortisolism in case 1 caused MODS, hyperglycemia, and electrolyte disturbances, which together likely contributed to the unfavorable outcome. Nevertheless, the exact cause of fulminant lung damage remains unknown in this case.

Contrary to the 71-year-old with severe hypercortisolism, the 66-year-old patient (case 3) with mild CD had asymptomatic COVID-19 in spite of the presence of the same clinical risk factors such as T2DM, hypertension, obesity, and advanced age. Similarly, a mild clinical presentation of COVID-19 was previously reported in a 71-year-old male patient with active CS [21] and in a 47-year-old female patient with rheumatoid arthritis receiving GCs [35].

In contrast, the 38-year-old (case 2) with moderately elevated cortisol levels had a typical clinical presentation of COVID-19. This young patient made a complete recovery with minimal signs of lung fibrosis assessed 3 weeks after being discharged, which may be due to the positive effects of hypercortisolism. 
Neither of our patients received treatment to resolve hypercortisolism due to various reasons. However, there is a clinical case of a 67-year-old man with CD who was hospitalized due to COVID-19 pneumonia receiving pasireotide and metyrapone. This patient developed adrenal insufficiency and required intravenous hydrocortisone [20]. $\mathrm{He}$ had several elevated inflammation markers, such as CRP $-57 \mathrm{mg} / \mathrm{L}$, D-dimer- $943 \mu \mathrm{g} / \mathrm{l}$. Repeated chest X-Ray showed progression of bilateral pneumonia. Nevertheless the overall outcome was favorable [20].

Based on our observational results, cytokine storm was possibly prevented in patients with CS. Following the cHIS criteria [7], the patient with the highest cortisol levels (case 1) had hematological dysfunction and signs of macrophage activation without fever, significant coagulopathy, hepatic injury, or increased inflammation markers based on CRP concentration. Thus, the damaging effects of COVID-19 in this case series were most likely different from previously reported features of hyperinflammation syndrome.

In summary, this clinical case series gives a first insight into the clinical and laboratory presentations of patients with ACTH-dependent CS and confirmed COVID-19 infection. It seems possible that the clinical course of COVID-19 is dependent on the severity of endogenous hypercortisolism. Based on our clinical findings, hypercortisolism was indeed beneficial at reducing nonspecific inflammation markers, which might prevent a severe course of COVID-19 and further lung fibrosis. However, severe hypercortisolism was associated with fulminant progression of pneumonia causing death. Thus, severe CS affected by COVID-19 is more likely to require emergency care despite a lack of clinical presentations and low inflammation biomarkers.

Acknowledgements The authors thank Geoffrey Clayson for English editing work. This research was supported by Ministry of Science and Higher Education of the Russian Federation (agreement no. 075-152020-899).

\section{Compliance with ethical standards}

Conflict of interest The authors declare no competing interests.

Ethics approval All procedures performed in studies involving human participants were in accordance with the ethical standards of the national research committee and with the 1964 Helsinki declaration and its later amendments. The study was approved by the local ethical committee of the NRMCE.

Informed consent Informed consent was obtained from all individual participants included in the study.

Publisher's note Springer Nature remains neutral with regard to jurisdictional claims in published maps and institutional affiliations.

\section{References}

1. N. Zhu, D. Zhang, W. Wang, X. Li, B. Yang, J. Song, X. Zhao, B. Huang, W. Shi, R. Lu, et al. A novel coronavirus from patients with pneumonia in China, 2019. N Engl J Med (2020). https://doi. org/10.1056/NEJMoa2001017.

2. W.J. Wiersinga, A. Rhodes, A.C. Cheng, S.J. Peacock, H.C Prescott. Pathophysiology, transmission, diagnosis, and treatment of coronavirus disease 2019 (COVID-19): a review. JAMA (2020). https://doi.org/10.1001/jama.2020.12839.

3. R. Mao, Y. Qiu, J.-S. He, J.-Y. Tan, X.-H. Li, J. Liang, J. Shen, L.-R. Zhu, Y. Chen, M. Iacucci, et al. Manifestations and prognosis of gastrointestinal and liver involvement in patients with COVID-19: a systematic review and meta-analysis. Lancet Gastroenterol Hepatol. (2020). https://doi.org/10.1016/S2468-1253 (20)30126-6.

4. M. Levi, J. Thachil, T. Iba, J.H. Levy. Coagulation abnormalities and thrombosis in patients with COVID-19. Lancet HaematoL. (2020). https://doi.org/10.1016/S2352-3026(20)30145-9.

5. S. Maggo, P. Dhull, A.P. Dubey, D. Brashier, A. Karan, N.K. Singh, K. Joshi, Cytokine storm syndrome in COVID-19: diagnosis and management strategies. Int. J. Health Sci. Res. 10, 140-149 (2020)

6. G. Li, Y. Fan, Y. Lai, T. Han, Z. Li, P. Zhou, P. Pan, W. Wang, D. $\mathrm{Hu}, \mathrm{X}$. Liu, et al. Coronavirus infections and immune responses. J. Med. Virol. (2020). https://doi.org/10.1002/jmv.25685.

7. B.J. Webb, I.D. Peltan, P. Jensen, D. Hoda, B. Hunter, A. Silver, N. Starr, W. Buckel, N. Grisel, E. Hummel, et al. Clinical criteria for COVID-19-associated hyperinflammatory syndrome: a cohort study. Lancet Rheumatol. (2020). https://doi.org/10.1016/S26659913(20)30343-X.

8. The RECOVERY Collaborative Group Dexamethasone in Hospitalized Patients with Covid-19-Preliminary Report. N Engl J Med (2020). https://doi.org/10.1056/NEJMoa2021436.

9. F. Liu, C. Ji, J. Luo, W. Wu, J. Zhang, Z. Zhong, S. Lankford, H. Huang, F. Lin, Y. Wang, et al. Clinical characteristics and corticosteroids application of different clinical types in patients with corona virus disease 2019. Sci. Rep. (2020). https://doi.org/10. 1038/s41598-020-70387-2.

10. V. Selvaraj, K. Dapaah-Afriyie, A. Finn, T.P. Flanigan, ShortTerm Dexamethasone in Sars-CoV-2 Patients. R. I Med J. 103, 39-43 (2013). (2020)

11. World Health Organization (2020): Corticosteroids for COVID19: living guidance. https://apps.who.int/iris/handle/10665/ 334125. Accessed 2 Sep 2020.

12. M.J. Young, C.D. Clyne, K.E. Chapman, Endocrine aspects of ACE2 regulation: RAAS, steroid hormones and SARS-CoV-2. J. Endocrinol. (2020). https://doi.org/10.1530/JOE-20-0260.

13. P.S. Hench, E.C. Kendall, The effect of a hormone of the adrenal cortex (17-hydroxy-11-dehydrocorticosterone; compound E) and of pituitary adrenocorticotropic hormone on rheumatoid arthritis. Proc. Staff Meet. Mayo Clin. 24, 181-197 (1949)

14. V. Guarnotta, R. Ferrigno, M. Martino, M. Barbot, A.M. Isidori, C. Scaroni, A. Ferrante, G. Arnaldi, R. Pivonello, C. Giordano. Glucocorticoid excess and COVID-19 disease. Rev. Endocr. Metab. Disord. (2020). https://doi.org/10.1007/s11154-020-09598-x.

15. V. Hasenmajer, E. Sbardella, F. Sciarra, M. Minnetti, A.M. Isidori, M.A. Venneri, The Immune System in Cushing's Syndrome. Trends Endocrinol. Metab. (2020). https://doi.org/10.1016/j.tem. 2020.04.004

16. Z.E. Belaya, L.Y. Rozhinskaya, N.V. Dragunova, et al. Metabolic complications of endogenous Cushing: patient selection for screening. Obesity Metab. (2013). https://doi.org/10.14341/20718713-5068. 
17. P. Kakodkar, N. Kaka, M. Baig, A comprehensive literature review on the clinical presentation and management of the pandemic coronavirus disease 2019 (COVID-19). Cureus (2020). https://doi.org/10.7759/cureus.7560.

18. R. Pivonello, R. Ferrigno, A.M. Isidori, B.M.K. Biller, A.B. Grossman, A. Colao, COVID-19 and Cushing's syndrome: recommendations for a special population with endogenous glucocorticoid excess. Lancet Diabetes Endocrinol. (2020). https:// doi.org/10.1016/S2213-8587(20)30215-1.

19. J. Newell-Price, L.K. Nieman, M. Reincke, A. Tabarin, Endocrinology in the time of COVID-19: Management of Cushing's syndrome. Eur. J. Endocrinol. (2020). https://doi.org/10.1530/ EJE-20-0352.

20. F. Beretta, F. Dassie, M. Parolin, F. Boscari, M. Barbot, L. Busetto, R. Mioni, E. De Carlo, C. Scaroni, F. Fallo, et al. Practical considerations for the management of Cushing's disease and COVID-19: a case report. Front. Endocrinol. (2020). https:// doi.org/10.3389/fendo.2020.00554.

21. A.L. Serban, E. Ferrante, G. Carosi, R. Indirli, M. Arosio, G. Mantovani, COVID-19 in Cushing disease: experience of a single tertiary centre in Lombardy. J. Endocrinol. Investig. (2020). https://doi.org/10.1007/s40618-020-01419-x.

22. G.A. Melnichenko, I.I. Dedov, Z.E. Belaya, L.Y. Rozhinskaya, G. R. Vagapova, N.I. Volkova, A.Y. Grigor'ev, E.N. Grineva, E.I. Marova, A.M. Mkrtumayn, et al. Cushing's disease: the clinical features, diagnostics, differential diagnostics, and methods of treatment. Probl. Endokrinol. (2015). https://doi.org/10.14341/ probl201561255-77.

23. L.K. Nieman, B.M.K. Biller, J.W. Findling, J. Newell-Price, M.O. Savage, P.M. Stewart, V.M. Montori, The diagnosis of Cushing's syndrome: an endocrine society clinical practice guideline. J. Clin. Endocrinol. Metab. (2008). https://doi.org/10.1210/jc.2008-0125.

24. L.K. Nieman, B.M.K. Biller, J.W. Findling, M.H. Murad, J. Newell-Price, M.O. Savage, A. Tabarin, Treatment of Cushing's syndrome: an endocrine society clinical practice guideline. J. Clin. Endocrinol. Metab. (2015). https://doi.org/10.1210/jc.2015-1818.

25. Z.E. Belaya, A.V. Iljin, G.A. Melnichenko, L.Y. Rozhinskaya, N. V. Dragunova, L.K. Dzeranova, S.A. Butrova, E.A. Troshina, I.I. Dedov, Diagnostic performance of late-night salivary cortisol measured by automated electrochemiluminescence immunoassay in obese and overweight patients referred to exclude Cushing's syndrome. Endocrine (2012). https://doi.org/10.1007/s12020-0129658-3.
26. D.W. Cain, J.A. Cidlowski, Immune regulation by glucocorticoids. Nat. Rev. Immunol. (2017). https://doi.org/10.1038/nri. 2017.1.

27. A.K. Singh, S. Majumdar, R. Singh, A. Misra, Role of corticosteroid in the management of COVID-19: a systemic review and a Clinician's perspective. Diabetes Metab. Syndr. (2020). https:// doi.org/10.1016/j.dsx.2020.06.054.

28. J. Wu, J. Huang, G. Zhu, Y. Liu, H. Xiao, Q. Zhou, X. Si, H. Yi, C. Wang, D. Yang, et al. Systemic corticosteroids show no benefit in severe and critical COVID-19 patients in Wuhan, China: a retrospective cohort study. Infect. Dis. (2020). https://doi.org/10. 1101/2020.05.11.20097709.

29. X. Lu, T. Chen, Y. Wang, J. Wang, F. Yan, Adjuvant corticosteroid therapy for critically ill patients with COVID-19. Crit. Care (2020). https://doi.org/10.1186/s13054-020-02964-w.

30. Y. Wang, W. Jiang, Q. He, C. Wang, B. Wang, P. Zhou, N. Dong, Q. Tong, A retrospective cohort study of methylprednisolone therapy in severe patients with COVID-19 pneumonia. Sig. Transduct. Target Ther. (2020). https://doi.org/10.1038/s41392020-0158-2.

31. R. Fadel, A.R. Morrison, A. Vahia, Z.R. Smith, Z. Chaudhry, P. Bhargava, J. Miller, R.M. Kenney, G. Alangaden, M.S. Ramesh, et al. Early short-course corticosteroids in hospitalized patients with COVID-19. Clin. Infect. Dis. (2020). https://doi.org/ 10.1093/cid/ciaa601.

32. T. Chroboczek, M. Lacoste, C. Wackenheim, T. Challan-Belval, B. Amar, T. Boisson, J. Hubac, D. Leduc, C. Masse, V. Dechaene, et al. Beneficial effect of corticosteroids in severe COVID-19 pneumonia: a propensity score matching analysis. Infect. Dis. (2020). https://doi.org/10.1101/2020.05.08.20094755.

33. C. Huang, Y. Wang, X. Li, L. Ren, J. Zhao, Y. Hu, L. Zhang, G. Fan, J. Xu, X. Gu, et al. Clinical features of patients infected with 2019 novel coronavirus in Wuhan, China. Lancet (2020). https:// doi.org/10.1016/S0140-6736(20)30183-5.

34. F. Zhou, T. Yu, R. Du, G. Fan, Y. Liu, Z. Liu, J. Xiang, Y. Wang, B. Song, X. Gu, et al. Clinical course and risk factors for mortality of adult inpatients with COVID-19 in Wuhan, China: a retrospective cohort study. Lancet (2020). https://doi.org/10.1016/ S0140-6736(20)30566-3.

35. Y. Han, M. Jiang, D. Xia, L. He, X. Lv, X. Liao, J. Meng, COVID-19 in a patient with long-term use of glucocorticoids: a study of a familial cluster. Clin. Immunol. (2020). https://doi.org/ 10.1016/j.clim.2020.108413. 